\title{
TRIPLE-PULSE INTEGRATED PATH DIFFERENTIAL ABSORPTION LIDAR FOR CARBON DIOXIDE MEASUREMENT- NOVEL LIDAR TECHNOLOGIES AND TECHNIQUES WITH PATH TO SPACE
}

\author{
Upendra N. Singh \\ NASA Engineering and Safety Center \\ NASA Langley Research Center \\ Hampton, Virginia, USA \\ Upendra.n.singh@nasa.gov
}

\author{
Tamer F. Refaat and Mulugeta Petros \\ Remote Sensing Branch \\ NASA Langley Research Center \\ Hampton, Virginia, USA
}

\begin{abstract}
The societal benefits of understanding climate change through identification of global carbon dioxide sources and sinks led to the desired NASA's active sensing of carbon dioxide emissions over nights, days, and seasons (ASCENDS) space-based missions of global carbon dioxide measurements. For more than 15 years, NASA Langley Research Center (LaRC) have developed several carbon dioxide active remote sensors using the differential absorption lidar (DIAL) technique operating at the two-micron wavelength. Currently, an airborne two-micron triple-pulse integrated path differential absorption (IPDA) lidar is under development. This IPDA lidar measures carbon dioxide as well as water vapor, the dominant interfering molecule on carbon dioxide remote sensing. Advancement of this triple-pulse IPDA lidar development is presented.
\end{abstract}

Keywords-carbon dioxide; water vapor; triple-pulse laser; lidar; DIAL; IPDA

\section{INTRODUCTION}

The lack of spatially extensive, high-accuracy atmospheric $\mathrm{CO}_{2}$ data limits the ability to construct accurate inverse estimates of the sources and sinks of the gas. ASCENDS study advocate an active $\mathrm{CO}_{2}$ remote sensing mission to provide critical global $\mathrm{CO}_{2}$ measurements [1]. Airborne full rangeresolved DIAL measurements of $\mathrm{CO}_{2}$ is beyond near-term technological capability. In absence of such capability airborne column dry-air volume mixing ratio of $\mathrm{CO}_{2}$ (XCO2) measurements weighted toward the boundary layer (BL) are ideal for studying $\mathrm{CO}_{2}$ sources and sinks [1][2][3]. This is achieved using the IPDA lidar technique, which relies on much stronger hard target return signals rather than weak atmospheric scattering [4]. In addition, an airborne instrument provides an excellent complement to the temporally-rich but spatially sparse in-situ measurement network. The BL weighted $\mathrm{XCO} 2$ data can be used to evaluate the ability of GOSAT and OCO-2 to detect spatial variability in lower tropospheric $\mathrm{CO}_{2}$. Simultaneous airborne measurement of column dry-air volume mixing ratio of $\mathrm{H}_{2} \mathrm{O}(\mathrm{XH} 2 \mathrm{O})$ enables the study of coupled carbon and water cycles [4][5][6].

For more than 20 years, researchers at LaRC have developed several high-energy and high repetition rate $2-\mu \mathrm{m}$ pulsed lasers and other critical components for $\mathrm{CO}_{2}$ DIAL instruments [7]. The 2- $\mu \mathrm{m}$ wavelength was targeted due to the existence of distinct absorption features for $\mathrm{CO}_{2}$ at this wavelength region [4]. Currently, LaRC team is engaged in designing, developing and demonstrating a triple-pulsed $2-\mu \mathrm{m}$ direct detection IPDA lidar to measure $\mathrm{XCO} 2$ and $\mathrm{XH} 2 \mathrm{O}$ from an airborne platform [4][8][9]. The unique wavelength control for each pulse allows measurement of the two most dominant greenhouse gases, simultaneously and independently, using a single instrument [10]. This work is an update for the $2-\mu \mathrm{m}$ double-pulse airborne IPDA lidar for $\mathrm{CO}_{2}$ measurement [11][12]. This paper provides background, status and details of the triple-pulse IPDA development, which enables several technologies for future space-based system for global $\mathrm{CO}_{2}$ measurement [8].

\section{TRIPLE-PULSE IPDA LIDAR TECHNIQUE}

Based on the successful demonstration of the double-pulse IPDA lidar, the triple-pulse IPDA lidar transmitter generates three successive laser pulses for every pump pulse [4][11][12]. The pump repetition rate is set to $50 \mathrm{~Hz}$. The three pulses are 150 to $200 \mu \mathrm{sec}$ apart and set to three different wavelengths, as shown schematically in Fig.1. Using an enhanced wavelength control scheme the wavelength of each of these pulses can be tuned and locked at different wavelength, as marked in Fig.2. One scenario of wavelength selection is demonstrated in the same figure. The $\mathrm{CO}_{2}$ on and off-line wavelengths are selected around the R30 line, so that both would have similar $\mathrm{H}_{2} \mathrm{O}$ absorption to minimizes water vapor interference on $\mathrm{CO}_{2}$ measurements. Similarly, $\mathrm{H}_{2} \mathrm{O}$ on- and off-line are selected around the nearest $\mathrm{H}_{2} \mathrm{O}$ absorption peak such that carbon dioxide interference is minimized in the $\mathrm{H}_{2} \mathrm{O}$ measurement. However, both $\mathrm{CO}_{2}$ on-line and $\mathrm{H}_{2} \mathrm{O}$ off-line measurements share the same wavelength, which enables simultaneous measurement of both molecules with three pulses rather than four pulses almost independently while avoiding interference from each other [4]. Other different measurement scenarios could be achieved with the same IPDA instrument just by tuning and locking the operating wavelengths of the three pulses to different positions.

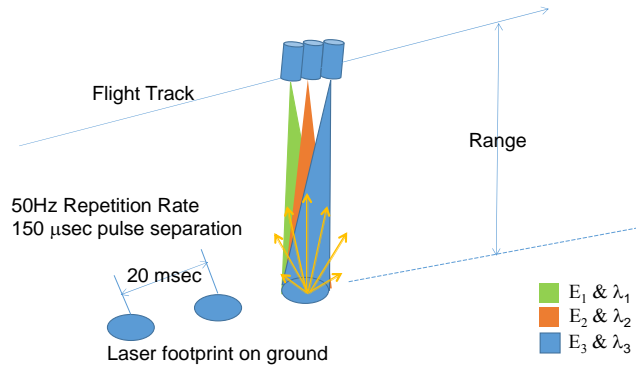

Figure 1. Airborne nadir 2- $\mu \mathrm{m}$ triple-pulse IPDA lidar concept. Each pulse is generated with different wavelength and energy. The three pulses are transmitted every $20 \mathrm{~ms}$, equivalent to $50 \mathrm{~Hz}$ repetition rate. Pulse separation of 150-200 ms results in higher than 95\% laser footprint overlap above $4 \mathrm{~km}$ altitude. 
For example, wavelength tuning allows measuring $\mathrm{CO}_{2}$ with two different weighting functions simultaneously as shown in Fig.3. Fig.3 indicates that the selected $\mathrm{CO}_{2}$ on-line wavelength is optimized for near-surface measurements. Shifting this wavelength by 67 or $75 \mathrm{pm}$ would tune the weighting function to optimize measurements in the $\mathrm{BL}$ or lower troposphere. This tuning feature results in a unique adaptive targeting capability. For an airborne IPDA lidar, adaptive targeting would tune and lock the instrument sensing wavelength to meet certain measurement objective depending on the target or Earth's surface condition and environment. Table 1 lists the double-pulse and triple-pulse 2- $\mu \mathrm{m}$ IPDA lidar transmitter parameters as compared to transmitter requirements for $\mathrm{CO}_{2}$ space-based active remote sensing. These space-based requirements were set by the European Space Agency (ESA) for a future $\mathrm{CO} 2$ active remote sensing mission at the $2-\mu \mathrm{m}$ wavelength [3][4][12].

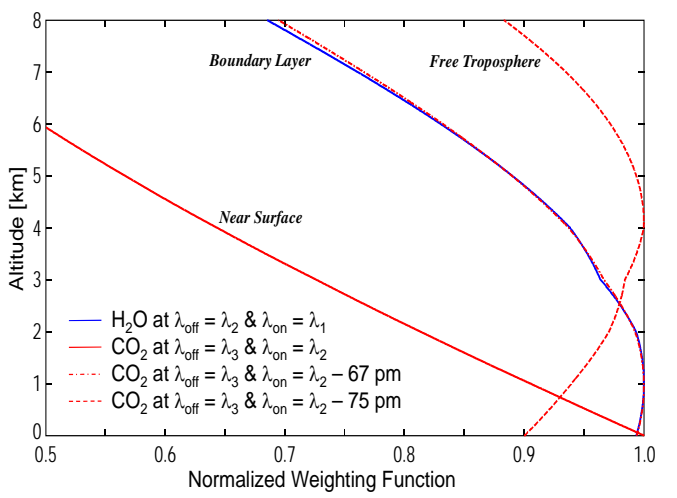

Figure 3. $\mathrm{H}_{2} \mathrm{O}$ and $\mathrm{CO}_{2}$ pressure-based normalized weighting functions versus altitude at selected spectral positions for an airborne nadir pointing IPDA measurement. $\mathrm{H}_{2} \mathrm{O}$ and $\mathrm{CO}_{2}$ measurements are weighted to the boundary layer and near the surface, respectively, for operating wavelength shown in Fig.2. Tuning $\mathrm{CO}_{2}$ on-line wavelength 67 and $75 \mathrm{pm}$ away from the selected location optimize the IPDA measurement to within the boundary layer or lower troposphere. [4]

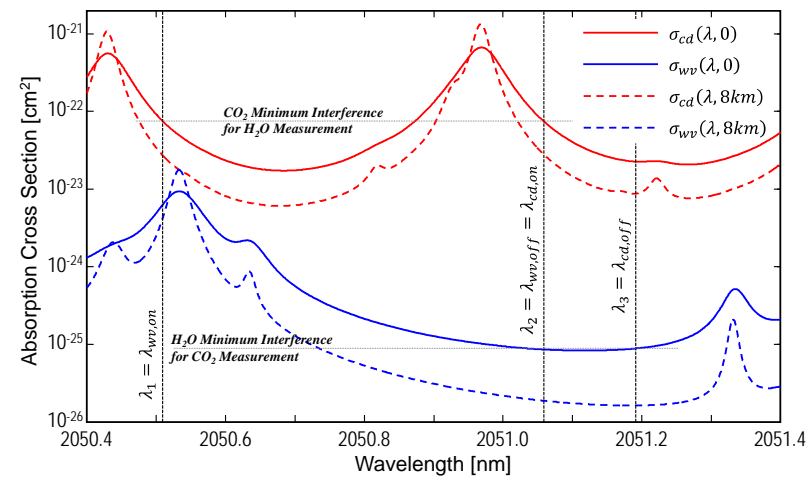

Figure 2. Comparison of the $\mathrm{H}_{2} \mathrm{O}$ and $\mathrm{CO}_{2}$ absorption cross-section spectra, $\sigma_{\mathrm{wv}}$ and $\sigma_{\mathrm{cd}}$, respectively, at ground $(0 \mathrm{~km})$ and mid-altitude aircraft $(8 \mathrm{~km})$. Temperature and pressure profiles used in the calculation were obtained from the US Standard atmospheric model. Vertical lines mark the instrument operating wavelengths for $\mathrm{CO}_{2}$ and $\mathrm{H}_{2} \mathrm{O}$ independent measurements. Note that $\lambda_{1}$ is the $\mathrm{H}_{2} \mathrm{O}$ on-line, $\lambda_{2}$ serves as the $\mathrm{H}_{2} \mathrm{O}$ off-line, and the $\mathrm{CO}_{2}$ on-line and $\lambda_{3}$ is the $\mathrm{CO}_{2}$ off-line. The horizontal lines point to minimization of molecular interference errors [4].

\section{TRIPLE-PULSE IPDA LIDAR TECHNOLOGY}

The 2- $\mu \mathrm{m}$ triple-pulse IPDA lidar consists of a laser transmitter, receiver and data acquisition system. The triplepulse IPDA laser transmitters is based on the Ho:Tm:YLF high-energy $2-\mu \mathrm{m}$ pulsed laser technology [7]. The generated $2-\mu \mathrm{m}$ laser beam is transmitted coaxially with the receiver telescope after beam expansion. Energy monitors, installed inside the laser enclosure, detect and measure the energy of each of the transmitted pulses [11]. The exact wavelengths of the three pulses are controlled by a wavelength control unit.

Table 1. Comparison of $\mathrm{CO}_{2}$ active remote sensing state-of-the-art 2- $\mu \mathrm{m}$ double-pulse and triple-pulse IPDA laser transmitters, developed at NASA LaRC, with ESA space requirements [4][7].

\begin{tabular}{lccc}
\hline & $\begin{array}{c}\text { Current } \\
\text { Technology }\end{array}$ & $\begin{array}{c}\text { Projected } \\
\text { Technology }\end{array}$ & $\begin{array}{c}\text { Space } \\
\text { Requirement }\end{array}$ \\
\cline { 2 - 4 } Transmitter & Single-Laser & Single-Laser & Two Lasers \\
Technique & Double-Pulse & Triple-Pulse & Single-Pulse \\
Cooling & Liquid & Conductive & --- \\
Wavelength $(\mu \mathrm{m})$ & 2.051 & 2.051 & 2.051 \\
Pulse Energy $(\mathrm{mJ})$ & $100 / 50$ & $50 / 15 / 5$ & $40 \& 5$ \\
Repetition Rate & $10 \mathrm{~Hz}$ & $50 \mathrm{~Hz}$ & $50 \mathrm{~Hz}$ \\
Power & $1.3 \mathrm{~W}$ & $3.5 \mathrm{~W}$ & $2.25 \mathrm{~W}$ \\
Pulse Width (ns) & $200 / 350$ & $30 / 100 / 150$ & 50 \\
Optical Efficiency & $4.0 \%$ & $5.0 \%$ & $5.0 \%$ \\
Wall-Plug Efficiency & $1.4 \%$ & $2.1 \%$ & $>2.0 \%$ \\
Multi-Pulse Delay & $200 \mu \mathrm{s}$ & $200 \mu \mathrm{s}$ & $250 \pm 25 \mu \mathrm{s}$ \\
Transverse Mode & $\mathrm{TEM} \mathrm{M}_{00}$ & TEM & $\mathrm{TEM}$ \\
Longitudinal Modes & Single Mode & Single Mode & Single Mode \\
Pulse Spectral Width & $2.2 \mathrm{MHz}$ & $4-14 \mathrm{MHz}$ & $>60 \mathrm{MHz}$ \\
Beam Quality (M ${ }^{2}$ ) & 2 & 2 & $<2$ \\
Freq. Control Accuracy & $0.3 \mathrm{MHz}$ & $0.3 \mathrm{MHz}$ & $0.2 \mathrm{MHz}$ \\
Seeding Success Rate & 99 & 99 & 99 \\
Spectral Purity & $99.9 \%$ & $99.9 \%$ & $99.9 \%$ \\
\hline
\end{tabular}

\section{A. Triple-Pulse Laser Transmitter}

The Ho:Tm:YLF triple-pulse laser is end pumped using $792 \mathrm{~nm} \mathrm{AlGaAs}$ laser diode arrays. This external pumping targets the Tm, which transfer the stored energy to the Ho relying on the different excitation lifetime. Relative to the pump pulse, Q-switch triggers produces up to three successive laser pulses with relatively controlled energies and pulsewidths. Fig. 4 compares the generated output laser energies for single, double and triple-pulse operation versus the pump laser energy. For three pulse arrangement time separation is approximately $150-200 \mu \mathrm{s}$. Thermal analysis was conducted to design proper heat dissipation out of the laser crystal to avoid permanent damage. A prototype oscillator with triple pulsing capability has already been demonstrated. Fig.5 shows a single-shot pulse record generated from the oscillator. Final laser configuration including thermal analysis and alignment optimization is currently on going to achieve higher energies. 


\section{B. Wavelength Control}

The objective of the wavelength control unit is to provide the required seeding for each of generated pulses. A study indicated that $\pm 1 \mathrm{MHz}$ on-line wavelength jitter is the dominant transmitter systematic error source using this triplepulse IPDA lidar for $\mathrm{CO}_{2}$ measurements [4]. This drives the need for a precise wavelength locking mechanism to reduce such error. The exact wavelengths of the pulsed laser transmitter are controlled by the wavelength control unit. The unique wavelength control of the triple pulses uses a single semiconductor laser diode, obtained from NASA Jet Propulsion Laboratory [13] and provides three different seeds of any frequency setting within $35 \mathrm{GHz}$ offset from the locked $\mathrm{CO}_{2} \mathrm{R} 30$ line center reference [10]. This unit includes several electronic, optical and electro-optic components which were acquired and characterized at NASA LaRC. Laser diode driver electronics results in a wavelength jitter of $\pm 6.1 \mathrm{MHz}$. This jitter is significantly reduced to $\pm 650.1 \mathrm{kHz}$ using center line locking electronics, which meets the jitter limit objective [4]. Fig. 6 shows an optical spectrum analyzer scans for the seeding wavelengths at 6,16 and $32 \mathrm{GHz}$ offset from the center line locking. Proper filters are included to eliminate harmonics from the generated wavelengths to maintain spectral purity.

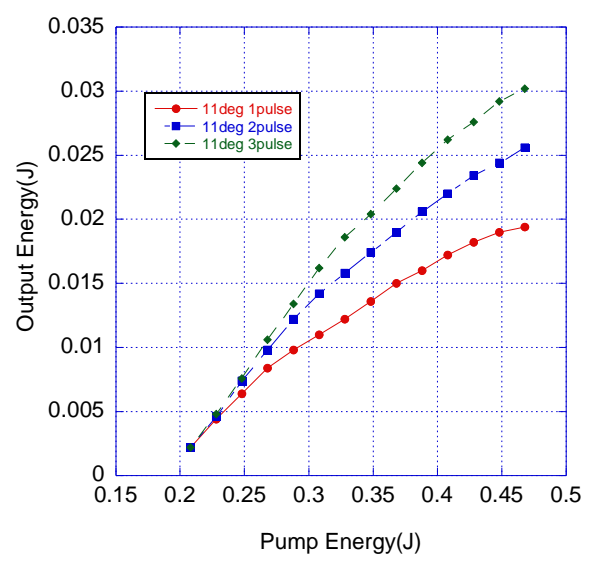

Figure 4. Total output pulse energy versus pump laser energy for the 2- $\mu \mathrm{m}$ IPDA transmitter for single-, double- and triple-pulse operation. Data presented for $50 \mathrm{~Hz}$ repetition rate and $2.5 \mathrm{~ms}$ long pump pulse.

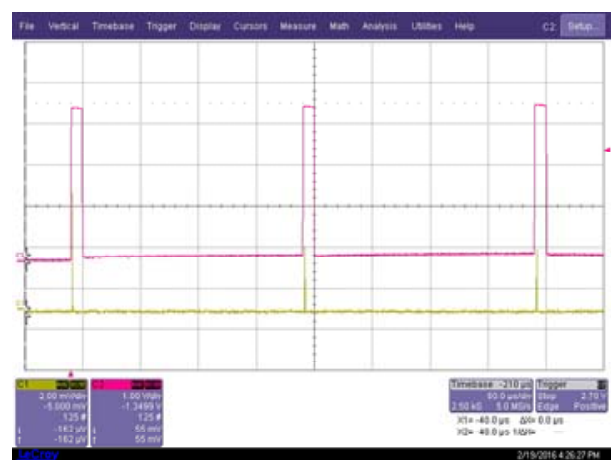

Figure 5. Oscilloscope record for a successful triple-pulse operation of the 2$\mu \mathrm{m}$ IPDA transmitter. The record shows the profiles of the three pulse (yellow) relative to the Q-switch triggers (red).
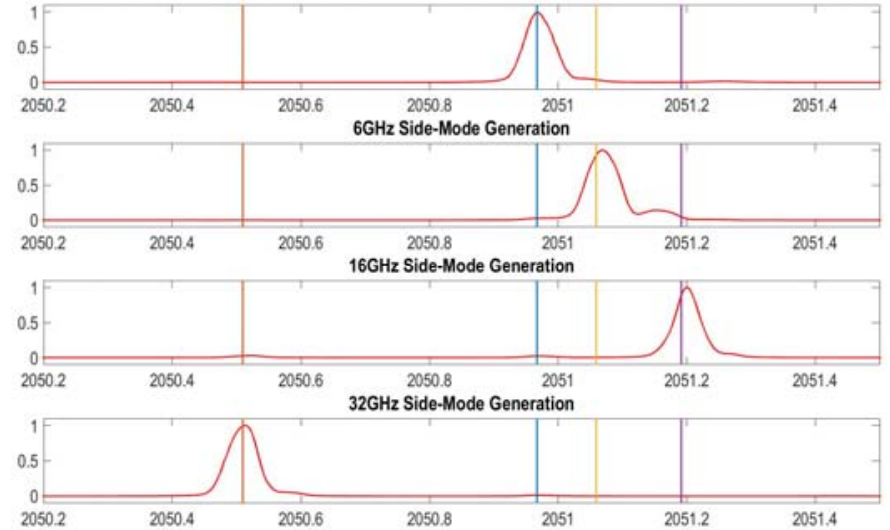

Figure 6. Optical spectrum analyzer scans for the reference wavelength locking to the $\mathrm{CO}_{2} \mathrm{R} 30$ line (top) and the different generated seeding wavelengths for the triple-pulse IPDA transmitter. Vertical lines mark the center line reference (blue), $6 \mathrm{GHz}$ (yellow), $16 \mathrm{GHz}$ (purple) and $32 \mathrm{GHz}$ (orange) spectral positions. Lines are broadened due to the analyzer resolution.

\section{IPDA Receiver and Detection Systems}

Similar to the double-pulse IPDA, the 2- $\mu$ m triple-pulse IPDA lidar receiver, shown schematically in Fig. 7, consists of a 0.4 $\mathrm{m}$ Newtonian telescope that focuses the radiation onto $300 \mu \mathrm{m}$ diameter spot. The telescope secondary mirror is a two surface dichroic flat. One surface turns the return radiation $90^{\circ}$ to the side integrated aft-optics. The opposite surface is used to transmit the expanded laser beam coaxially with the telescope. A single automated mount is used for bore-sight alignment. The radiation collected by the telescope is focused, collimated, filtered then applied to a 90/10 beam splitter. The 90\% signal channel is an exact replica of the double-pulsed lidar using an InGaAs pin photodiode detection system. The $10 \%$ channel is planned to be used with an advanced $\mathrm{HgCdTe}$ (MCT) electroninitiated avalanche photodiode (e-APD) detection channel. These MCT e-APD devices are space-qualifiable and were validated for airborne lidar operation at $1.6-\mu \mathrm{m}$ at NASA Goddard Space Flight Center (GSFC) [14]. In co-ordination with NASA Earth Science Technology Office (ESTO), LaRC is collaborating with GSFC to integrate this detector into the 2$\mu \mathrm{m}$ IPDA. This e-APD exhibit less than $0.5 \mathrm{fW} / \mathrm{Hz}^{1 / 2}$ noiseequivalent-power (NEP) and is expected to enhance the $2-\mu \mathrm{m}$ IPDA detection performance by expanding the dynamic range and reducing random errors.

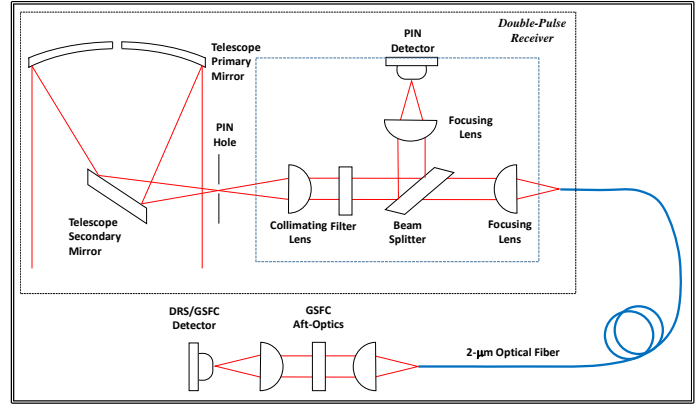

Figure 7. 2- $\mu \mathrm{m}$ triple-pulse IPDA receiver system, integrated based on the previous double-pulse system. The receiver consists of a telescope, aft optics with high-signal InGaAs channel and low-signal e-APD channel. The e-APD channel is coupled through an optical fiber through additional aft-optics. 
MCT e-APD are sensitive to IR radiation up to 4- $\mu$ m. Therefore, a cold narrow band-pass filter is desired to limit the device background. In co-ordination with ESTO, LaRC collaborated with GSFC to integrate the detector into the triplepulse $2-\mu \mathrm{m}$ IPDA lidar. This e-APD comes with 4 by 4 pixel format $\left(80 \times 80 \mu \mathrm{m}^{2}\right.$ pixel area) with read-out electronics that enable access to each pixel through individual TIA. An output summing amplifier would produce the sum of specific number of pixels as selected by the operator. The detector is integrated inside a vacuum chamber, which allows cooling the device with cryo-cooler down to $70 \mathrm{~K}$ to reduce dark current and noise. The e-APD and readout electronics are integrated inside a rack mountable chassis, shown in the same figure, which includes vacuum circuit for thermal isolation. Additional custom designed aft-optics allows focusing the radiation onto selected number of pixels. The e-APD custom aft-optics is coupled to the IPDA aft-optics through a $2-\mu \mathrm{m}$ optical fiber, as shown in Fig. 7. Work efforts at GSFC included 2- $\mu \mathrm{m}$ cold filter integration to the detector chamber, detector assembly testing, additional aft-optics design with optical fiber coupling [14][15].

\section{CONCLUSIONS}

A 2- $\mu \mathrm{m}$ double-pulse IPDA lidar instrument have been developed at NASA LaRC. This instrument was validated for active remote sensing of carbon dioxide in the atmosphere. As an upgrade, a 2- $\mu \mathrm{m}$ triple-pulse IPDA lidar instrument is being developed at NASA LaRC. This novel active remote sensing IPDA instrument targets and measures both atmospheric carbon dioxide and water vapor. Wavelength selection and laser transmitter operation allows measuring both species independently and simultaneously. This would be the first demonstration of measuring two different atmospheric molecules with a single instrument. The instrument design is based on knowledge gathered through the previously successful $2-\mu \mathrm{m}$ double-pulse IPDA. Critical enhancements were implemented in the new triple-pulse design that advances the technology. These enhancements includes both the transmitter and receiver. For the transmitter, modifications include triple-pulse operation of the laser, laser timing control updates and wavelength control design. In the receiver, updates includes telescope integration, data acquisition system and additional high performance e-APD detector. The e-APD detector supplied by NASA GSFC, is a state-of-art, space qualifiable device that was validated for lidar applications. Combining both the $2-\mu \mathrm{m}$ triple-pulse transmitter with this new detector in a single instrument will result in a $\mathrm{CO}_{2}$ IPDA lidar with enabling technology, which meets or exceeds space requirements. Work progress of the $2-\mu \mathrm{m}$ triple-pulse IPDA program is on schedule. Instrument validation plans are under discussions to collaborate with different institutes with similar interests.

\section{ACKNOWLEDGMENT}

This work was funded and supported by NASA Earth Science Technology Office. The authors acknowledge the support of NASA Jet Propulsion Laboratory and NASA Goddard Space Flight Center.

\section{REFERENCES}

[1] Active Sensing of $\mathrm{CO}_{2}$ Emissions over Nights, Days, and Seasons (ASCENDS) Mission, NASA Science Definition and Planning Workshop Report, University of Michigan (2008).

[2] K. Jucks, S. Neeck, J. Abshire, D. Baker, E. Browell, A. Chatterjee, D. Crisp, S. Crowell, S. Denning, D. Hammerling, F. Harrison, J. Hyon, S. Kawa, B. Lin, B. Meadows, R. Menzies, A. Michalak, B. Moore, K. Murray, L. Ott, P. Rayner, O. Rodriguez, A. Schuh, Y. Shiga, G. Spiers, J. Wang, and T. Zaccheo, "Active Sensing of $\mathrm{CO}_{2}$ Emissions over Nights, Days, and Seasons (ASCENDS) Mission", Science Mission Definition Study (2015).

[3] P. Ingmann, P. Bensi, Y. Duran, A. Griva, and P. Clissold, "A-Scope advanced space carbon and climate observation of planet earth", ESA Report for Assessment, SP-1313/1 (2008).

[4] T. Refaat, U. Singh, J. Yu, M. Petros, S. Ismail, M. Kavaya, and K. Davis, "Evaluation of an airborne triple-pulsed $2 \mu \mathrm{m}$ IPDA lidar for simultaneous and independent atmospheric water vapor and carbon dioxide measurements", Applied Optics, vol. 54, pp. 1387-1398 (2015).

[5] J. Tadic, M. Loewenstein, C. Frankenberg, L. Iraci, E. Yates, W. Gore and A. Kuze, "A comparison of in-situ aircraft measurements of carbon dioxide to GOSAT data measured over Railroad Valley playa, Nevada, USA", Atmospheric Measurement Techniques Discussions, vol. 5, 5641 (2012).

[6] D. Hammerling, A. Michalak and S. Kawa, "Mapping of $\mathrm{CO} 2$ at high spatiotemporal resolution using satellite observations: Global distributions from OCO-2", Journal of Geophysical Research, vol. 117, D06306 (2012).

[7] U. Singh, B. Walsh, J. Yu, M. Petros, M. Kavaya, T. Refaat, and N. Barnes, "Twenty years of Tm:Ho:YLF and LuLiF laser development for global wind and carbon dioxide active remote sensing", Optical Materials Express, vol. 5, pp. 827-837 (2015).

[8] U. Singh, T. Refaat, M. Petros, and J. Yu, "Triple-pulse two-micron integrated path differential absorption lidar: a new active remote sensing capability with path to space", in EPJ Web of Conferences, 27th International Laser Lidar Conference, vol. 119, 02001 (2016).

[9] U. Singh, M. Petros, T. Refaat, and J. Yu, "2-micron triple-pulse integrated path differential absorption lidar development for simultaneous airborne column measurements of carbon dioxide and water vapor in the atmosphere", Proc. of SPIE, vol. 9879, 987902, 2016.

[10] T. Refaat, M. Petros, C. Antill, U. Singh, and J. Yu, "Wavelength locking to $\mathrm{CO} 2$ absorption line-center for $2-\mu \mathrm{m}$ pulsed IPDA lidar application", Proc. SPIE, vol. 9879, 987904 (2016).

[11] T. Refaat, U. Singh, M. Petros, R. Remus and J. Yu, "Self-calibration and laser energy monitor validation for a double-pulsed $2-\mu \mathrm{m} \mathrm{CO} 2$ integrated path differential absorption lidar application", Applied Optics, vol. 54(24), pp. 7240-7251 (2015).

[12] T. Refaat, U. Singh, J. Yu, M. Petros, R. Remus, and S. Ismail, "Doublepulse $2-\mu \mathrm{m}$ integrated path differential absorption lidar airborne validation for atmospheric carbon dioxide measurement", Applied Optics, vol. 55(15), pp. 4232-4246 (2016).

[13] M. Bagheri, G. Spiers, C. Frez, S. Forouhar, and F. Aflatouni, "Linewidth measurement of distributed-feedback semiconductor lasers operating near $2.05 \mu \mathrm{m}$," IEEE Photonics Technology Letters, vol. 27(18), pp. 1934-1937 (2015).

[14] X. Sun, J. Abshire, and J. Beck, "HgCdTe e-APD detector arrays with single photon sensitivity for space lidar applications", Proc. SPIE, vol. 9114, 91140K (2014).

[15] J. Beck, T. Welch, P. Mitra, K. Reiff, X. Sun, and J. Abshire, "A highly sensitive multi-element $\mathrm{HgCdTe}$ e-APD detector for IPDA lidar applications", Journal of Electronic Materials, vol. 43(8), pp. 2970-2977 (2014). 